\title{
Çatlama Adlı Küçürek Öyküsünde Düalizm
}

\author{
Nurcamal Ermekbaeva \\ Ardahan Üniversitesi, Çağdaş Türk Lehçeleri, Yüksek Lisans Öğrencisi
}

\begin{abstract}
Özet
"Küçük olan güzeldir" fikrini öne süren modern çağ zamanın hızına yetişmek için her şeyin küçüğünü, püf noktasını tercih eder. Modern çağnın ürünü olan küçürek öyküler de kısa fakat yoğun düşünceler gizleyen eser türleridir. Küçürek öyküler bu çağdaki olumsuz görünüşleri yansıtmakla bu olumsuzluklar dile getiren yazarın bir çı̆̆lığı olarak kabul edilir. Bir anlık zaman dilimini yansıtan öyküler karakterleri (genelde 1 ve 3 karakterden oluşur) açımlamaya, öğütte bulunmaya gücü yetmez, dolayısıyla küçürek öyküdeki tamamlanmamışlık olabilirliklere kapı açar.

Şeza Bargus’un Çatlama küçürek öyküsü başlık dahil 22 sözcük, 4 tümceden oluşan düalist unsurlar barındırdığı öyküdür. Düalizm en genel anlamıyla birbirine bağlı fakat iki karşıt bir unsur, prensipdir. Öyküdeki düalizm de ikililiğe ve zıtlığa işaret ettiği gibi, birbirine bağlı iki karşı değerlerin bütünüdür. Bütünün, aslın ikiye bölünmesi, asıl olanın ortadan kalkmasıdır. Asıl olanın yok olması, hiçliğin veya sahteliğin ortaya çıkmasıdır. Dolayısıyla öyküdeki düalizm: a) Modernleşen insanın modernleşmekle gelenek ve göreneklerine, insanlık özelliklerine, ve kendine yabancı kalması; b) Anne karnındaki çocuğun kararsızlığı ve dünyaya gelmekte tereddütte ve ikililikte bulunması şeklinde çözümlenebilir.

Anahtar Kelimeler: küçürek öykü, düalizm, modernizm, ötekileşme.
\end{abstract}

\section{Düalizm in Çatlama Short Story}

\begin{abstract}
The modern world suggesting the idea of "Small is beautiful" trying to keep up with the speed of time, prefers the point of everything. Short stories are the product of modern era that are short but includes intense thoughts. Problems in this age are reflected in short stories, thus short stories are considered like a call of the author. Short stories reflected a momentory period of time do not advice and explain characters, therefore the incompleteness opens the door to possibilities.

The Çatlama short story by Şeza Bargus consists of 22 words with the title, and 4 sentences that included dualistic elements. Dualism is a factor that connected to each other, but the two oppising principles. The dualism in the story points out to duality and antinomy, thus the dualism is totality of interdependent two opposite values. Dividing of original means disappearing of original. Consequently, the dualizm of the story is explained further: a) By modernizing human stay away from traditions and customs, human characteristics and himself. b) Indecision of the unborn child and hesitation to come to this world.
\end{abstract}

Key Words: Short story, dualism, modernism, otherness

\section{“Çatlama}

O şehirde kapıların tuhaf bir özelliği var.

İçlerinden biri, kapıya anahtarı soktuğunda iki kişiye bölünüyor;

biri dışarıda kalıyor, öteki içeri giriyor.”

\section{Giriş}

"Küçük olan güzeldir" fikrini öne süren modern çağ (Toffler, 2008: 330) zamanın hızzına yetişmek için her şeyin küçüğünü, püf noktasını tercih eder. Modern çağnın ürünü olan küçürek öyküler de kısa fakat yoğun düşünceler gizleyen eser türleridir. Küçürek öyküler bu çağdaki olumsuz görünüşleri yansıtmakla bu olumsuzlukları dile getiren yazarın bir çı̆̆lığı olarak kabul edilir. Bir anlık zaman dilimini yansitan öyküler karakterleri (genelde 1 ve 3 karakterden oluşur) açımlamaya, öğütte bulunmaya gücü yetmez, dolayısıyla küçürek öyküdeki tamamlanmamışlık olabilirliklere kapı açar.
Şeza Bargus’un Çatlama adlı küçürek öyküsü başlık dahil 22 sözcük, 4 tümceden oluşan düalist unsurlar barındırdığ öyküdür. Düalizm birbirine bağlı fakat iki karşıt unsur, prensiplerdir. Düalizm en temel anlamiyla, -düalizmin önde gelen temsilcileri- Platon ve Descartes'in beden ve ruh, zihin ve maddecilik ilkeleridir. Platon ve Descartes'in düalizmi insanın maddi yönünün yanı sıra bir de maddi olmayan bir yanının olduğunu savunur. Descartes ve Platon'a göre zihin insanın maddi olmayan tarafidır yani ruh maddi yapıda değildir, dolayısıyla zihin de ruha aittir. Böylece insanın beden ve ruhtan meydana geldiğini düşünmekle zihin ile bedenin etkileştiğini de ileri sürerler. Ne var ki bu etkileşimi açıklamazlar. Düalizmin öncüleri Platon ile Descartes'1n dışında tüm düalist filozofların düşünceleri, bu iki filozofun düşünceleri çerçevesinde gelişir.

Çin felsefesinde Yin ve Yang sembolü de bu tür zıtlıkların bütünüdür. Gecenin içinde aydınlık ve sıcağın; gündüzün içinde de soğuk ve gölge bölgelerin bulunması, dişi bölgede erkek görünümü ve erkek bölgede dişi görünümün olması olumluluk ve olumsuzlukların birbiri olmadan var olamadığını, birine diğerinden ayrı 
bakılamayacağını gösterir. Öyküdeki düalizm de ikililiğe ve zitlığa işaret ettiği gibi, birbirine bağlı iki karşı değerlerin bütünüdür. Düalizm bir açıdan bir aslın/orijinalin değerinin, bütünlügüun kaybolmasıdır. Aslın ortadan kalkması asıl olmayanın yüzeye çıkmasıdır. Dolayısıyla düalizm bir sorunun, tehlikenin, iyi olmayanın simgesidir. Öyküdeki düalizm bir insanın ikiye bölünmesi olarak simgelenir: içlerinden biri kapıya anahtarı soktuğunda iki kişiye bölünüyor, biri dışarıda kalıyor, öteki içeriye giriyor. Öyküdeki düalizmi iki aşamada değerlendirilebilir:

1. Anne karnındaki çocuk ve dünya

2. Modernizm ve ötekileşme

\section{2. Öyküdeki imgeler}

Öyküdeki bir diğer simgesel anlamdaki unsurlar kapı ve anahtardır. Öyküdeki kapı kapalı, açılması gereken bir kapıdır. Kapının kapalı olması sırların gizliliğine işaret eder. Bilinmeyen herşey sırdır. Sırların açımlanması ancak kapının açılmasıyla gerçekleşir. Sırların ortaya çıkması için anahtar niteliği taşır. Anahtar bir yeniliğe kavuşmanın -genelde olumlu anlamda- ufukların açılmasının simgesidir.

Kapıya anahtarın sokulmasıyla açılan kapıda kişi ikiye bölünür. Bu da kapının tuhaf bir özelliğidir. Biri dışarıda kalıyor, ötekisi içeriye giriyor. Kapı anahtarla açılmakla kolaylıkla bir durumdan ikinci bir duruma geçişi simgelemekle; ayrıca bir kurtuluşu ve geçmiş düşüncelerin, sorunların unutulmasını temsil eder. Öte yandan öyküde kapıdan giren kişinin zihninde bir çatlama, kararsızlık, ikililik vardır. Yarısı dışarıda kalır. Yani kişinin yeniliğe (öyküde ise modernizme ve bu dünyaya) eksik girmesidir.

\section{Anne karnındaki çocuk ve dünya düalizmi}

İnsan nasıl insan olmalıdır.

\section{(C. Aytmatov)}

Sadece modern çağda değil, insanlar geçmişten beri hegemonisini kanıtlama çabası içinde olmuşlardır. Son 2 bin 500 yılın yalnızca 230 senesi barış içinde geçmiştir (Wright, 2007: 4). Bu durum insanlığın vahşi, ihtiraslı ve acımasız yönünü ortaya koyar niteliktedir. Bu toplumun değil insanın iktidara olan hırsı, üstün olma isteğinden kaynaklanmıştır. Yani "krallar arasındaki savaşlar bitmiş, milletler arasındaki savaşlar başlamıştır" (Huntington, 2006: 24). Diğer bir ifadeyle, milletler kültürü, geçmişi, dili ve özellikle dini açısından birbirinden farklılaşır; artık millet olarak şekillenen toplum, yeniden üstün olma isteğine kapılır. Çünkü toplum insanlardan oluşur. Fakat modern çağın insanı kendi sırlarını bulmaya çalışan insan değil, kendini yaratmaya çalışan insandır. Modern çağ insanı özgürleştirmez, onu kendini geliştirme zorunluluğuyla baş başa bırakır. Modern çağın insanı olmak karmaşık ve zor bir sürecin nesnesi olmaktır (Foucault, 2011: 183,184). Modern çağda ister din kaynaklı çatışmalar ister silahlı savaşlar olsun, dünyanın korkunç bir mekan haline gelmesi henüz anne karnında şekil almamış embriyoların bile bu dünyaya gelme isteğini törpüler (Aytmatov, Kassandra Damgası). Embriyoların kainatta bulunmak istememesi metaforik anlamda kainatın kirlenmiş, bozulmuş, insanlıktan çıkmış varlıklarını uyandırmaktır. Bütün bu savaşlarda dinin bile etkisi kalmamış, aksine din yüzünden toplumlar savaşmaya devam etmiştir. Aytmatov bugünün dininin bugünkü şartlarına uyamadığını, bütün dinlerin birleşmesiyle savaşların bitmesini istemektedir (Söylemez, 2010: 24).

İkinci olarak dinde, geleneksel anlayışta ve doğa standartları dışında çocukların dünyaya gelmesi, daha doğmamış çocukların ve insanların kaderinin insanlar tarafından yazılması Huxley, Orwell ve Rand'da olduğu gibi aklın imanı geçmesi kişilikleri silinmiş, yarı insanların ortaya çıkmasının nedenidir.

Üçüncü olarak, modern çağ akıl almaz hızda teknolojik açıdan oldukça faydalı ürünler üretmekle doğanın dengesini bozmaktadır. Aşırı rekabet insanların insanlıktan çıkmasına, ruhsuzluğun, sevginin kaybolup gitmesine neden olmaktadır.

İnsanlar böyle sistemler üretmekle bugünün tanrısı olarak kendilerini seçmektedir. Öyleyse insanlar ne zaman insan olur.

Öyküde de kapının tuhaf olması, şehrin tuhaflığına işaret eder. Şehir şehir olmaktan çok huzur vermeyen, acımasız, kaotik, insanı yutabilecek canavar bir dünya olarak algılanır. Dolayısıyla anne karnındaki çocuk dünyaya gelmekte tereddüt eder. Çocuk doğmadan önce geleceği mekanın düzelmesini ister. Anne karnı yani içerisi güvenilir bir yerdir. Saflı̆̆ın simgesidir.

\section{Modernleşme ve ötekileşme düalizmi}

Modern çağ özellikle bu devrin ikinci dalgası duyguların arka plana, zekanın ön plana çıktığı bir devirdir. İnsan hiç, akıl her şeydir. Geleneksel olandan kopuş, yalnızlaşma, pragmatizm, parçalanmış hayat, umutsuzluk, aile sisteminin bozulması ve rekabet modern çağın başlıca özellikleridir. Bugün kesinlikle bir şey ters gidiyor diyen fütürist Toffler oldukça doğru tasnifte bulunur. Modern çağın hızına ayak uydurmaya çalışan insan parçalanmakta, yalnızlaşmakta, aile sistemi tanınmaz hale gelmektedir. Yalnızlaşan insan o yalnızlığı gidermek için uyuşrurucu, alkol kullanmakta ancak kendinden geçme durumunun sona ermesiyle tekrar yalnızlık hissini yaşamaktadır. Modern çağda yalnızlıktan kurtulmanın diğer yolu da cinsel ilişkide bulunmaktır. Bu da aynı alkol ve uyuşturucunu etkisi gibi bir anlıktır (Fromm, 1995: 20). Yalnızlıktan kaçmak için insan toplum gibi olmaya çalışmaktadır. Kendisi olmamakta, öteki gibi olmaktadır. Kendisi değil toplum gibi davranmaktadır. Fakat topluma uyduklarının farkında değildir modern insan. Peki modern çağın yalnızlaştırdığı insan hangi sebepler yüzünden ötekileşmektedir (insanlıktan çıkarlar). Fromm çalışma düzenine dikkat çekmektedir. Modern çağın insanına üniforma giydirilmiş gibidir. Çünkü kendi seçimlerinde özgür değildir. Fromm modern çağda insanların farkına varmadan robot rolünü oynadıklarını, aslında insanların tam anlamıyla özgür olmadıklarını dile getirmektedir:

"Hepsi yönetmeliğin kararlaştırdığ görevleri,kararlaştırılan bir hızla, kararlaştırılan yolda yürütürler. Duygular bile ısmarlamadır: Neşe, anlayış, güven, tutku, kimseyle çatışmadan geçinebilme. Böylesine zorlayıcı yollarla olmasa da eğlenme düzeni bile önceden belirlenmiştir. Kitapları kitap kulüpleri, filmleri filmcilerle sinemacılar ve bunların parayla yazdırdıkları reklamlar kararlaştırır; bunlardan artakalanlar da tekdüzedir hep: Arabayla pazar gezintisi, televizyon saati, kağıt oyunları, toplantılar. Doğumdan ölüme, pazartesinden pazartesiye, sabahtan akşama her şey sıraya dizilmiş, önceden belirlenmiştir. Böylesine düzenlenmiş sıralı işler ağına düşen kişi, insan olduğunu, tek bir birey olduğunu, umutları, umut 
kırıklıkları, üzüntüleri, korkuları, sevgi özlemi, hiçlik ve yalnızlık korkusuyla yaşama olanağının eline yalnız bir kez geçtiğini nasıl olur da unutamaz?" (Fromm, 1995: 24).

Metropollerin bulunduğu ülke modernleşen ülkedir ve bu şehirlerde insanlar trafik beklerken, bilgisayarda sorun oluştuğunda veya internetin kopması durumunda bile sinir krizi geçirmesine yetiyor. Gelişmiş ülkelerde insanların beyin çatlamaları veya psikolojik sorunları ciddi şekilde toplumu işgal eder. Alkol ve uyuşturucu bağımlılı̆̆ının artması, intihar oranının yükselmesi, böylesi modernleşen toplumlarda daha fazla görülmektedir. Modernleşmek insanları kendileri olmaktan çok ötekileşmeye, insana haz özelliklerden kopmasına neden olur. "Ötekileş(tir)ilen kişi, bilerek veya bilmeyerek yaşa(tıl)dığ bu süreçte, düşünce ve eylemlerindeki kendi'ne özgu'lüğü yitirmiş; başkaya dönüşmüş veya başkada batmış, kaybolmuş Ben'dir"(Korkmaz, 2008: 18). Modern insan bilime, aydınlığa erişmekle aynı anda ruhi özelliklerinden, insanlıktan çıkmaktadır.

Geleneksel ülkelerde (ise) modernleşme farklı etkiler gösterir. Modernleşmenin Batı'da ortaya çıkmış olmasıyla modernleşme yolunda olan toplumların da Batılılaşmasına neden olmaktadır. Modernleşmekle geleneksel olandan kopma toplumun parçalanmışlı̆̆ına, arada kalmışlığa, yabancılaşmaya sürüklemektedir. Yabancılaşma, öznenin bir başkasının isteği çerçevesinde farkına varmadan değişmesidir. Çeşitli isteklerden dolayı, başkaları tarafından seçilmiş tepkisiz kimlik'leri kabul etmektir. Diğer yönden sosyal hafızanın, toplumun tinsel doğumunu sağlayan kaynakların artık toplum hafizasından bilgisayar hafizasına aktarılması bu kaynaklar toplum aklında canlıyken pasif hale gelir (Toffler, 2008: 226). Dolayısıyla, geleneksel toplumlarda modern mankurt, ötekileşen toplumların ve bireylerin ortaya çıkması söz konusudur. "Dünya çapındaki sosyal değişme ve ekonomik modernleşme süreçleri, insanları çok eski mahalli kimliklerinden koparmaktadır. Bunlar aynı zamanda, bir kimlik kaynağı olarak milli devleti zayıflatı"" (Huntington, 2006: 27). Geleneksel olandan kopuş bir milletin otorite ve milli zenginliklerini yitimesiyle bu milletin başka milletlerin kültürü içerisinde kaybolup gitmesi halidir.

5. İçeridelik ve dışarıdalık diyalektiği

Dışarıda kalmak mı iyi içeriye girmek mi, ontolojik anlamda dışarısı dışarı mıdır, içerisi içerisi midir. Bir yerin sınırlarını belirten sadece yürektir (Kundera, 2012: 122). İçerdelik ve dışardalık birer göstergedirler, varlığın nerede içeride mi yoksa dışarıda $\mathrm{m}$ i bulunduğunu ancak insan belirtebilir o anki ruhi durumuna göre içerisi ve dışarısının sıfatını belirlenebilir. İçerisi ve dışarısı ancak niteleyici sözlerdir (Bachlard, 2008: 308). İçerdelik ve dişardalık dialektisi bir araya geldi mi olumlu ve olumsuzluğu da çağrıştırır. Neden hem içerisi, hem dışarısı aynı anda iyi veya kötü olamaz. Neden bu ikisi zitlığı oluşturur? Öyküdeki anahtar yeniliğe kavuşma, sırların açılmasını sağlayan unsurdur. Anahtarla kapının açılıp içeriye girilmesi bir yeniliğe ulaşmak olarak algılanır. Dışarıda kalan ise bu yeniliğe ulaşamayandır. Dolayısıyla içerisi modernizmi simgeler, dışarısı da yabancılaşmayı. İçerisi kapalı bir alan olduğu için bir koruma, ocak ve genelde ev olarak algılanır, dışarısı yurtsuzluğu, terkedilimişliği simgeler. Böylece içerdelik hem anne karnındaki çocuklar için, hem çağdaş insanın güvenilir açık bir mekanıdır. Öyleki bu mekanda insan aydınlanır, yeniliğe kavuşur. Yani insanların dünayadaki sırları keşvettiği aklın saygı kazandığı mekandır. Dışarısı geleneksel olandan koptuğu için labirentleşmekte ve karmaşıklaşmaktadır. Yani insanların umutsuzlaştığı geleneksel olandan koptuğu kapalı mekandır.

İnsanın modernleşmesi ve aydınlanması aynı zamanda ötekileşmesine neden olmaktadır: (a) özgün olamama, toplum gibi olma, (b) insan olamama, insansızlaşma ve insansızlaştırma (c) milli olamama, yabancılaşma.

\section{Sonuç}

Sonuç olarak öyküde düalizm yani ikilik olumlu bir anlama işaret etmez. Modernizm ve ötekileşme, anne karnındaki çocuk ve dünya düalizmi, Çin felsefesinde olduğu gibi Yin ve Yang, Platon ve Descartes'in ruh ve beden anlayışının etkileşiminin gölgesidir. İki karşıt unsur biri diğeri olmadan yaşaması zor olan, aynı anda birbirine karşı gelen değerlerdir. Aynı anda ikililik bir bütünün kaybolmasıdır. Bütünün, aslın ikiye bölünmesi, aslın ortadan kalkmasıdır. Asıl olanın yok olması, hiçliğin veya sahteliğin ortaya çıkmasıdır. Bu da öyküde modernleşen insanın kendi gelenek ve göreneklerine, insanlık özelliklerine ve kendine yabancı kalması; anne karnındaki çocuğun kararsızlığı ve dünyaya gelmekte tereddüt etmesi şeklinde çözümlenir. Kapı ve anahtar bu iki unsurun iletiş̧imine kolaylık sağlayan, öyküdeki gizliği aydınlatan, hakiki durumu yakalamaya yardımcı olan birer sembollerdir. Kapı, modernizm ile ötekileşme arasında kalan topluluğun bir durumdan ikinci bir duruma, çocuğun anne karnından dünyaya geçişini sağlayan unsurdur. Anahtar gizlerin açılmasında kolaylık sağlayarak öyküde modernliğe ve aydınlanmaya kolayca geçebilmesine imkan tanır. Ancak bu toplum geleneklerine bağlı kalmakta zorlanır.

İçerdelik ve dışardalık dialektisi öyküdeki düalizmi açımlar. İçerisi aydınlık, açık bir mekandır, çünkü anahtar sırların açılmasını simgeler. Dolayısıyla bölünen kişinin birinin kapıyı anahtarla açarak girebilmesi sırları keşfettiğini ve aydınlığa ulaştığına işaret eder. Ötekisi ise içeriye girememiş, bu sırları keşfedememiş tarafıdır. Bu anlamda dışarısı kapalı bir mekandır. Metaforik açıdan kişinin ikiye bölünmesi, kişinin beynindeki çatlama, kararsızlık, yeniliği tamamıyla kabul edemediğini ve ayrıca eksik yönlerinin mevcut olduğunu gösterir.

Böylece Çatlama küçürek öyküsünün, yazarın geçmişi boyunca izlediği dünyada oluşmuş sorunlara dönük bir haykırışı olduğu söylenebilir.

\section{Kaynaklar:}

Bachlard, G., (2008), Uzamın Poetikası (çev. Alp Tümertekin), İthaki Yay., s. 308, İstanbul.

Bargus, Ş., (2008), Şeza Bargus'tan Dört Kıpkısa Öykü (çev. İbrahim Demirci), Hece Öykü, 27, Haziran-Temmuz.

Foucault, M., (2011), Özne ve İktidar (çev. Iş̧ı Ergüden, Osman Akınhay), Ayrıntı Yay., s. 183-184, İstanbul.

Fromm, E., (1995), Sevme Sanatı (çev. Yurdanur Salman), Payel Yay., s. 20, 24, İstanbul.

Korkmaz, R., (2008), Aytmatov Anlatılarında Ötekileşme Sorunu ve Dönüş İzlekleri, Grafiker Yay., s. 18, Ankara.

Kundera, M., (2012), Roman Sanatı (çev. Aykut Derman), Can Yay., s. 122, İstanbul.

P. Huntington, S., (1995), Medeniyetler Çatışması, Vadi Yay., s. 24,27, Ankara. 
Söylemez, O., (2010), Cengiz Aytmatov: Tematik İncelemeler, Atatürk Kültür Merkezi Yay., s. 24, Ankara.

Toffler, A., (2008), Üçüncü Dalga (çev. Sevim Yeniçeri), Koridor Yay., s.226, 330, İstanbul.

Wright, R., (2007), İlerlemenin Kısa Tarihi (çev. Zarife Biliz, Barış Baysal), Versus Yay., s. 4, İstanbul. 